\title{
Synthesis, Characterization, and Photocatalytic Properties of Flower-like Mn-doped Ceria
}

\author{
Pei Li ${ }^{a b}$, Wei Zhang ${ }^{a}$, Xun Zhang ${ }^{a}$, Zhengde Wang ${ }^{a}$, Xianpeng Wang ${ }^{a}$, Songlin Ran ${ }^{b}$, Yaohui Lv $v^{a}$ (D) \\ ${ }^{a}$ School of Materials Science and Engineering, Anhui Key Laboratory of Metal Materials and \\ Processing, Anhui University of Technology, Anhui, Maanshan, 243002, China \\ ${ }^{b}$ Key Laboratory of Metallurgical Emission Reduction \& Resources Recycling, Ministry of Education, \\ Anhui University of Technology, Anhui, Maanshan, 243002, China
}

Received: March 05, 2018; Revised: May 22, 2018; Accepted: June 08, 2018

\begin{abstract}
Mn-doped $\mathrm{CeO}_{2}$ flower-like microstructures have been synthesized by a facile one-step compositehydroxide-mediated method. The structure, morphology, optical and the surface properties of $\mathrm{Mn}$ doped $\mathrm{CeO}_{2}$ have been investigated by X-ray diffraction (XRD), field-emission scanning electron microscopy (FESEM), UV-Vis absorption spectroscopy and X-ray photoelectron spectroscopy (XPS). The XRD results confirmed the successful incorporation of $\mathrm{Mn}$ into the $\mathrm{CeO}_{2}$ lattice through the formation of face-centered cubic solid solution. The photocatalytic activities of the catalysts were evaluated by measuring the photodegradation efficiency of Rhodamine $\mathrm{B}(\mathrm{RhB})$ under ultraviolet light irradiation. With an optimal molar ratio of $1 \%$ in $\mathrm{Mn} / \mathrm{CeO}_{2}$ the highest rate photodegradation was achieved under the experimental conditions. The enhanced photocatalytic activity can be attributed to the incorporation of multivalent $\mathrm{Mn}$ in $\mathrm{CeO}_{2}$ promoted the separation of photogenerated charges, inhibited the recombination of photogenerated carriers, and thus prolonged the charges lifetime to participate in the photocatalytic reaction.
\end{abstract}

Keywords: Cerium oxide, Manganese doped, Photocatalysis.

\section{Introduction}

Semiconductor-based photocatalysis has emerged as one of the most attractive techniques to convert sunlight into chemical energy so as to remove organic pollutants from wastewater for environmental remediation. Among various semiconductor materials, as a high-efficiency, nontoxicity, abundant, photochemical stability and low-cost promising photocatalyst, $\mathrm{CeO}_{2}$ has been an extensively investigated material for environmental pollution removal and photocatalytic hydrogen evolution ${ }^{1-3}$. Nevertheless, some drawbacks limit its practical application in the photocatalyst region, including rapid recombination rate of photogenerated electron-hole pairs, low quantum yield in the reactions, and very poor response to visible light. Therefore, from the viewpoint of photochemistry, numerous methods for suppression of these drawbacks have been attempted to improve $\mathrm{CeO}_{2}$-based photocatalytic activities. To the best of our knowledge, one of approaches is to develop $\mathrm{CeO}_{2}$ based heterostructure semiconductor systems, such as TiO $@$ @Pt@ $\mathrm{CeO}_{2}{ }^{4}, \mathrm{Au} / \mathrm{CeO}_{2}{ }^{5,6}, \mathrm{CdS} / \mathrm{CeO}_{2}{ }^{7}, \mathrm{SrTiO}_{3} / \mathrm{CeO}_{2}{ }^{8}, \mathrm{Bi}_{2} \mathrm{O}_{3} / \mathrm{CeO}_{2}{ }^{9}$, $\mathrm{TiO}_{2} / \mathrm{CeO}_{2}{ }^{10,11}$ and $\mathrm{Cu}_{2} \mathrm{O} / \mathrm{CeO}_{2}{ }^{12}$. On the other hand, there have been modifications of $\mathrm{CeO}_{2}$ by doping non-metallic species $^{13,14}$ and crystal facet engineering ${ }^{15,16}$. For instance, Zhu et al. ${ }^{13}$ reported the synthesis of $\mathrm{N}$-doped $\mathrm{CeO}_{2}$ nanoparticles with controllable doping levels at the nanoscale through a reliable wet chemical approach, showing enhanced visiblelight sensitivity and photocatalytic activity. Fuertes et al. ${ }^{14}$ have doped nitrogen into ceria powder by sintering $\mathrm{CeO}_{2}$ in $\mathrm{NH}_{3}$ flow at very high temperature. Recent reports have shown that $\mathrm{CeO}_{2}$ nanostructures with highly active exposed crystal planes such as $\{100\}$ and $\{110\}$ can significantly enhance their catalytic activity ${ }^{15}$. Meanwhile, the selective metal doping of $\mathrm{CeO}_{2}$ to improve its performance started to appear in the literature. Recently, the metal doping of $\mathrm{CeO}_{2}$ has also been examined in solar cell devices ${ }^{17}$, but the corresponding photocatalytic investigations are relatively few.

It has been reported that doping with multivalent transition-metal (TM) cations was considered an effective method to inhibit the recombination of photogenerated carriers in semiconductors ${ }^{18}$. Theoretical investigation showed that among the $3 \mathrm{~d}$ metals, Mn has the greatest potential in permitting significant optical absorption in the visible or even the infrared solar light, through the combined effects of narrowed band gap and the introduction of intermediate bands within the forbidden gap ${ }^{19,20}$. Recently, there have been many reports on Mn-doped oxide photo-activity under UV and visible light, such as $\mathrm{Mn}-\mathrm{ZnO}^{21-24}, \mathrm{Mn}-\mathrm{TiO}_{2}{ }^{25,26}$, where $\mathrm{Mn}$ exists in the bivalence oxidation state.

Inspired by above-mentioned investigations, flower-like $\mathrm{Mn}$-doped $\mathrm{CeO}_{2}$ photocatalyst was obtained via a simple onestep composite-hydroxide-mediated method. In addition, we demonstrated the enhanced photocatalytic performance of the $\mathrm{Mn}$ doped $\mathrm{CeO}_{2}$ flower-like nanostructures by degradation of Rhodamine $\mathrm{B}(\mathrm{RhB})$ solutions, and further investigated the impact of $\mathrm{Mn}$ doping concentrations of doped $\mathrm{CeO}_{2}$ on the resulting photocatalytic activities under ultraviolet light. 


\section{Experimental}

\subsection{Material preparation}

Pure and flower-like $\mathrm{Mn}$-doped $\mathrm{CeO}_{2}$ nanostructure were obtained by a simple one-step composite-hydroxide-mediated method according to our group previously report with tiny modification ${ }^{27}$. In a typical preparation process, (1) a total of $20 \mathrm{~g}$ of $\mathrm{KOH}$ and $\mathrm{KI}$ was mixed at a ratio of 70.6:29.4 and placed in a $25 \mathrm{~mL}$ Teflon vessel. (2) Different molar ratio of $\mathrm{MnSO}_{4} \cdot \mathrm{H}_{2} \mathrm{O}$ and $\mathrm{CeO}_{2}$ was used as the raw material for reaction, and was placed on the top of the hydroxide in the vessel. (3) The Teflon vessel was put into a furnace preheated to $235{ }^{\circ} \mathrm{C}$. (4) After the hydroxide was totally molten (30 min later), the molten reactants were mixed uniformly by shaking the covered vessel. (5) 24 hours later, the vessel was taken out and cooled to room temperature naturally. The as-prepared samples were removed from the solution, rinsed thoroughly several times with deionized water and ethanol to remove residual salts, and subsequently dried for $12 \mathrm{~h}$ at vacuum circumstance. The as-prepared samples in the subsequent discussion in this paper are denoted as $x \%$ $\mathrm{Mn} / \mathrm{CeO}_{2}$, where $x \%$ refers to the $\mathrm{Mn} /(\mathrm{Mn}+\mathrm{Ce})$ molar ratio.

\subsection{Catalyst characterization}

The crystal structure of the resultant products was characterized by X-ray powder diffraction (XRD) by using a Bruker AXS D8 advance powder diffractometer with $\mathrm{Cu}$ $\mathrm{K} \alpha$ radiation $(\lambda=0.154056 \mathrm{~nm})$. Field-emission scanning electron microscope (FESEM, S-4800) was employed to characterize the morphologies and size of the synthesized $\mathrm{Mn}$ doped $\mathrm{CeO}_{2}$ samples. UV-vis diffuse reflectance spectra were obtained for the dry-pressed disk samples by using a Shimadzu UV 2550 recording spectrophotometer, which was equipped with an integrating sphere, and $\mathrm{BaSO}_{4}$ was used as a reference. X-ray photoelectron spectroscopy (XPS) measurements were performed on a Thermo Fisher Scientific Escalab 250 spectrometer with monochromatized Al $\mathrm{K} \alpha$ excitation, and $\mathrm{C}_{1 \mathrm{~s}}(284.6 \mathrm{eV})$ was used to calibrate the peak positions of the elements. The Raman-scattering experiments were carried out using NEXUS 670 Raman spectrometer at room temperature. The $473 \mathrm{~nm}$ line of the solid-state laser was used for excitation.

\subsection{Catalyst activity}

The photocatalytic performance of the as-prepared samples was characterized by decomposing $\mathrm{RhB}$ under ultraviolet light irradiation at room temperature. The photocatalytic experiments were carried out by adding $100 \mathrm{mg}$ photocatalysts into $300 \mathrm{~mL}$ of $10 \mathrm{mg} \mathrm{L}^{-1} \mathrm{RhB}$ solution in the vessel. A 300 W Hg arc lamp (XPA-1, Nanjing XuJiang Electromechanical Plant) was used as the light source. Prior to the irradiation, the suspensions were magnetically stirred in the dark for $30 \mathrm{~min}$ to establish the adsorption/desorption equilibrium.
After different irradiation time, the concentration of the $\mathrm{RhB}$ solution was measured on a UV-Vis spectrophotometer (Hitachi UV-3100).

\section{Results and Discussion}

The X-ray diffraction (XRD) patterns of $\mathrm{Mn}_{\mathrm{x}} \mathrm{Ce}_{1-\mathrm{x}} \mathrm{O}_{2}$ photocatalysts are shown in Figure 1 along with pure $\mathrm{CeO}_{2}$. The diffraction peaks of pure $\mathrm{CeO}_{2}$ can be indexed to the fluorite cubic phase of $\mathrm{CeO}_{2}$ (JCPDF card: 65-2975) with lattice constant $\mathrm{a}=0.5411 \mathrm{~nm}$. The diffraction pattern of $\mathrm{Mn}_{\mathrm{x}} \mathrm{Ce}_{1-\mathrm{x}} \mathrm{O}_{2}$ photocatalysts was similar to that of pure $\mathrm{CeO}_{2}$. The XRD pattern does not show any impurity/additional peaks for any Mn doping concentration. This clearly confirms that the Mn ions occupy positions within the fluorite-lattice. Furthermore, the extended X-ray diffraction pattern of $\mathrm{Mn}_{\mathrm{x}} \mathrm{Ce}_{1-\mathrm{x}} \mathrm{O}_{2}$ photocatalysts reveals a slight shift in the peak positions towards larger angles with increasing $\mathrm{Mn}$-concentration, which may be due to the lattice reduction of $\mathrm{CeO}_{2}$ upon $\mathrm{Mn}$ ions doping. Because the ionic radius of $\mathrm{Mn}^{\mathrm{n}+}\left(\mathrm{Mn}^{4+}=0.53 \AA, \mathrm{Mn}^{3+}=0.645 \AA, \mathrm{Mn}^{2+}=0.83 \AA\right)$ is smaller than that of $\mathrm{Ce}^{4+}(1.01 \AA)$, when $\mathrm{Mn}^{\mathrm{n}+}$ embedded in $\mathrm{CeO}_{2}$ lattice and takes the place of $\mathrm{Ce}^{4+}$, the contraction and distortion of the ceria lattice occur, leading to the decrease of the cell parameter ${ }^{28}$. In present study, the existence of the $\mathrm{Mn}^{\mathrm{n}+}$ oxidation state in $\mathrm{Mn}_{\mathrm{x}} \mathrm{Ce}_{1-\mathrm{x}} \mathrm{O}_{2}$ photocatalysts will be discussed in the later section.

Figure 2 shows the morphology and size of the source material $\mathrm{CeO}_{2}$ (a) and the flower-like $1 \% \mathrm{Mn}$-doped $\mathrm{CeO}_{2}$ sample (b) obtained by typical field-emission scanning electron microscope (FESEM). The anomalous particles morphology of the source material $\mathrm{CeO}_{2}$ can be seen with the diameter ranging from $2-8 \mu \mathrm{m}$ (Figure 2 a). From the high-magnification SEM images shown in Figure $2 \mathrm{~b}$, it can be seen that the flower-like micro-/nano-architectures are

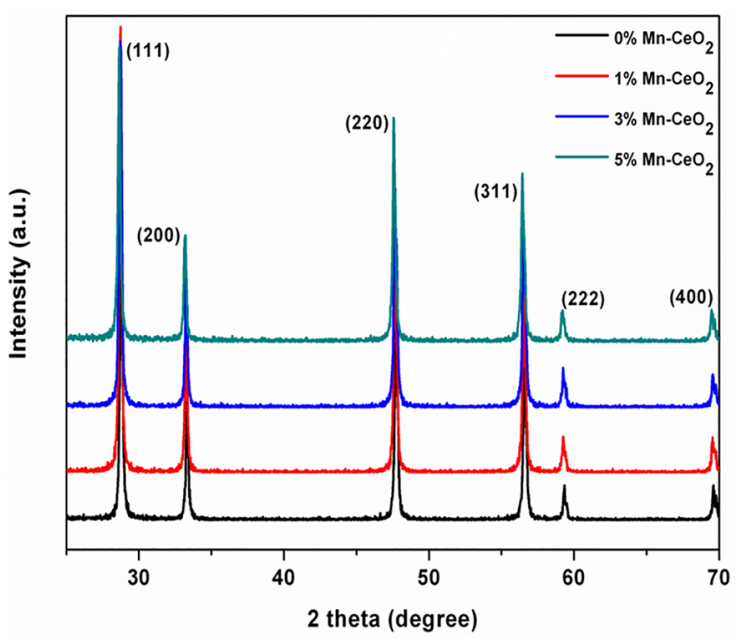

Figure 1. XRD patterns of Mn-doped $\mathrm{CeO}_{2}$ from different mole concentrations of Mn source 
built from dozens of flake-like nanopetals with the average diameter of $1-4 \mu \mathrm{m}$.

The effect of Mn substitution on cubic fluorite structure of $\mathrm{CeO}_{2}$ lattice is further confirmed using $\mathrm{UV}$-visible optical spectroscopy measured in the range of 200-800 nm. Figure $3 \mathrm{a}$ shows the room-temperature optical absorption spectra of undoped and flower-like $\mathrm{Mn}$-doped $\mathrm{CeO}_{2}$ photocatalyst. The absorbance spectra for $1 \% \mathrm{Mn}$-doped $\mathrm{CeO}_{2}$ sample was found to increase when compared to the undoped $\mathrm{CeO}_{2}$ sample. However, the absorbance intensity for the 3 and $5 \% \mathrm{Mn}$-doped $\mathrm{CeO}_{2}$ sample were found to decrease when compared to the undoped $\mathrm{CeO}_{2}$ sample. This may be due to the electron-electron, electron-donor atom and electronhole interactions which increase drastically as doping is increased beyond a critical limit ${ }^{29,30}$. These interactions dominate the electron-photon interactions. A plot of variation of $(\alpha h v)^{2}$ versus $h v$, which is obtained according to the Kubelka-Munk function transformation, is shown in
Figure $3 \mathrm{~b}$. The evaluated band gap values for the pure and the $1 \% \mathrm{Mn}$-doped $\mathrm{CeO}_{2}$ sample were observed to be 3.05 $\mathrm{eV}$ and $2.88 \mathrm{eV}$, respectively. It could be seen that the band gap value slightly decreased when the dopant concentration of Mn was increased.

Raman scatting is an effective tool for the investigation of the effects of doping on nanomaterials, as the incorporation of dopants leads to shifts of the lattice Raman vibrational peak positions. Figure 4 displays the Raman spectra of pure $\mathrm{CeO}_{2}$ as well as $\mathrm{Mn}$-doped $\mathrm{CeO}_{2}$ samples with different $\mathrm{Mn}$ contents. For the pure $\mathrm{CeO}_{2}$ sample, a strong peak at $461 \mathrm{~cm}^{-1}$ can be assigned to the $\mathrm{F}_{2 \mathrm{~g}}$ Raman active mode of the cubic fluorite structure of $\mathrm{CeO}_{2}$, which is due to the symmetric breathing mode of the oxygen atoms around cerium ions. Compared to the pure $\mathrm{CeO}_{2}$, the peak intensity decreased greatly and became broader and red-shifted for the Mndoped $\mathrm{CeO}_{2}$ samples. The red-shift could be attributed to the changes in lattice parameter with crystallite size, as it
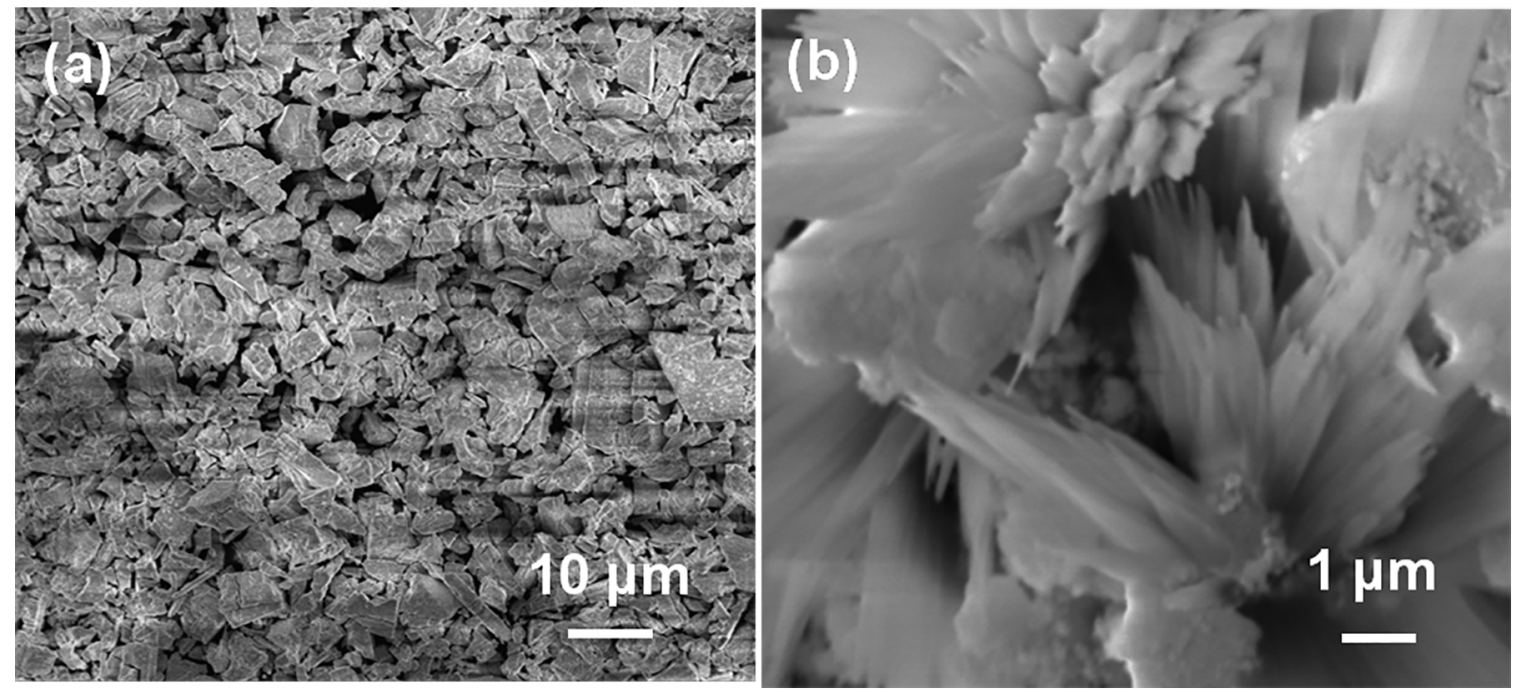

Figure 2. FESEM images of (a) pure $\mathrm{CeO}_{2}$ raw materials; (b) $1 \% \mathrm{Mn} / \mathrm{CeO}_{2}$ sample
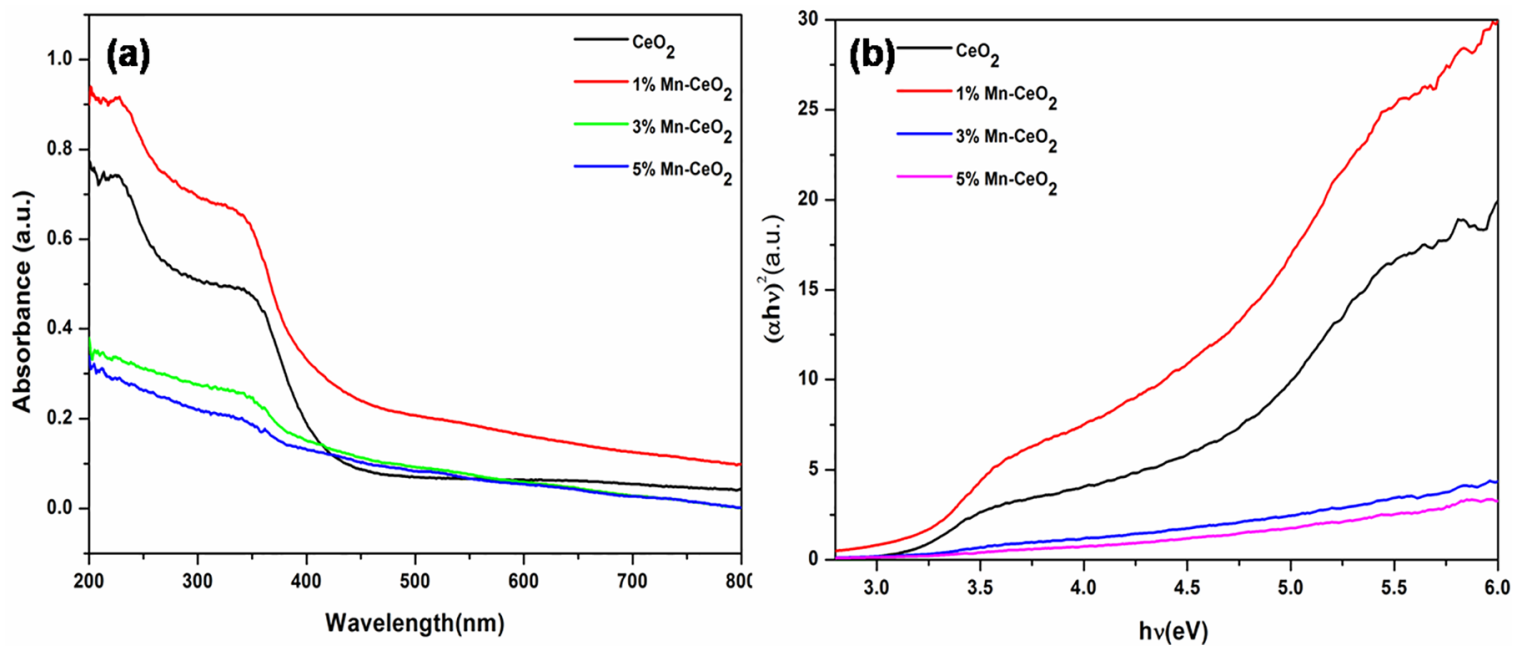

Figure 3. (a) UV-Vis absorption spectra of $\mathrm{Mn} / \mathrm{CeO}_{2}$ with varying $\mathrm{Mn} / \mathrm{Ce}$ molar ratio; (b) Plot of $(\alpha h v)^{2}$ versus photon energy of pure and $\mathrm{Mn}$-doped $\mathrm{CeO}_{2}$ samples 


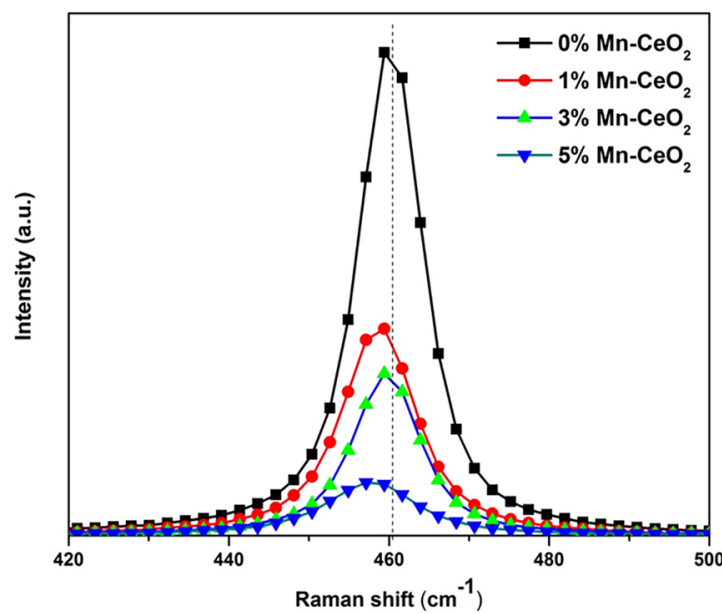

Figure 4. Raman spectra of $\mathrm{Mn} / \mathrm{CeO}_{2}$ with varying $\mathrm{Mn} / \mathrm{Ce}$ molar ratio

was previously explained by phonon confinement model ${ }^{31,32}$. Another reason of shifting and broadening may be the increase in oxygen vacancies, which is related to structural defects derived from partially incorporation of manganese into $\mathrm{CeO}_{2}$ lattice. In the $\mathrm{Mn}$-doped $\mathrm{CeO}_{2}$ samples, the extra oxygen vacancies were generated by the incorporation of $\mathrm{Mn}$ ion into the ceria fluorite lattice to compensate for the valence mismatch between the $\mathrm{Mn}^{\mathrm{n}+}$ and $\mathrm{Ce}^{4+}$ ions.

The chemical states of the Mn doping in the as-prepared samples were then investigated by XPS, as presented in Figure 5a, the XPS survey spectra indicated that the asprepared $\mathrm{Mn}$ doped $\mathrm{CeO}_{2}$ nanoflowers were composed of $\mathrm{Ce}, \mathrm{O}$ and $\mathrm{Mn}$ elements. Figure $5 \mathrm{~b}$ shows the XPS spectra of the $\mathrm{Mn} 2 \mathrm{p}$ region. The double peaks with binding energies of ca. $641.0 \mathrm{eV}$ and $653.1 \mathrm{eV}$ correspond to the characteristic of Mn $2 \mathrm{p}_{3 / 2}$ and Mn $2 \mathrm{p}_{1 / 2}$ signals, respectively. Since XPS signals for $\mathrm{Mn}^{2+}$ and $\mathrm{Mn}^{3+}$ are very close to each other $\sim 641.0$ $\mathrm{eV}$ for the $\mathrm{BE}$ of $\mathrm{Mn} 2 \mathrm{p}_{3 / 2},{ }^{33}$ thus the coexistence of $\mathrm{Mn}^{2+} /$
$\mathrm{Mn}^{3+}$ ion couple in the $\mathrm{Mn}$-doped $\mathrm{CeO}_{2}$ samples. Here, the $\mathrm{Mn} 2 \mathrm{P}_{3 / 2}$ peak is deconvoluted with the Gaussian-Lorenz model functions, and two peaks at $641.2 \mathrm{eV}$ and $642.3 \mathrm{eV}$ can be assigned to the $\mathrm{Mn}^{2+}$ and $\mathrm{Mn}^{3+}$ ions, respectively, according to the standard binding energy and previous literature. ${ }^{3}$ This results suggest the coexistence of $\mathrm{Mn}^{2+}$ and $\mathrm{Mn}^{3+}$ ions on the surface of samples. In addition, we can observe that the XPS peaks show some noise, implying that the content of Mn ions at the surface of the sample is low and Mn ions have been doped into the interior of the nanostructure.

The effective incorporation of $\mathrm{Mn}^{2+}$ ions into $\mathrm{CeO}_{2}$ crystalline lattices can greatly enhance the light photocatalytic performance. The UV-vis spectral changes of RhB solution over $1 \% \mathrm{Mn}$ doped $\mathrm{CeO}_{2}$ samples during the photodegradation are shown in Figure 6a, clearly show that the characteristic absorption peaks corresponding to $\mathrm{RhB}$ decrease rapidly as the exposure time increases, indicating the decomposition of $\mathrm{RhB}$ and the significant reduction in the $\mathrm{RhB}$ concentration. Figure $6 \mathrm{~b}$ shows the results of $\mathrm{RhB}$ photodegradation over $\mathrm{Mn}$ doped $\mathrm{CeO}_{2}$ samples with different $\mathrm{Mn}$ doping concentrations. After 210 min of irradiation, the photodegradation efficiencies of RhB were about 65,40 and $30 \%$ for 1,3 and $5 \% \mathrm{Mn}$ doped $\mathrm{CeO}_{2}$ samples, respectively. It was evident that $1 \%$ $\mathrm{Mn}$ doped $\mathrm{CeO}_{2}$ samples exhibited excellent photocatalytic activities for the $\mathrm{RhB}$ degradation. However, the photocatalytic performance of $\mathrm{Mn}$ doped $\mathrm{CeO}_{2}$ samples decreased with the increase of $\mathrm{Mn}$ doped amount. The results show that there was an optimal $\mathrm{Mn}$ doping concentration in $\mathrm{CeO}_{2}$ samples for the ultraviolet light photocatalysis ( $1 \% \mathrm{Mn}$ dopant). When the Mn doping concentration was further increased, the Mn dopant sites could be also act as efficient recombination centers with increased recombination rate due to the reduced average distance between trapped carriers ${ }^{34}$. The excess Mn dopant sites could greatly decrease the number of charge carriers and deteriorate the photocatalytic performance of doped $\mathrm{CeO}_{2}$ samples, as identified from Figure $6 \mathrm{~b}$.
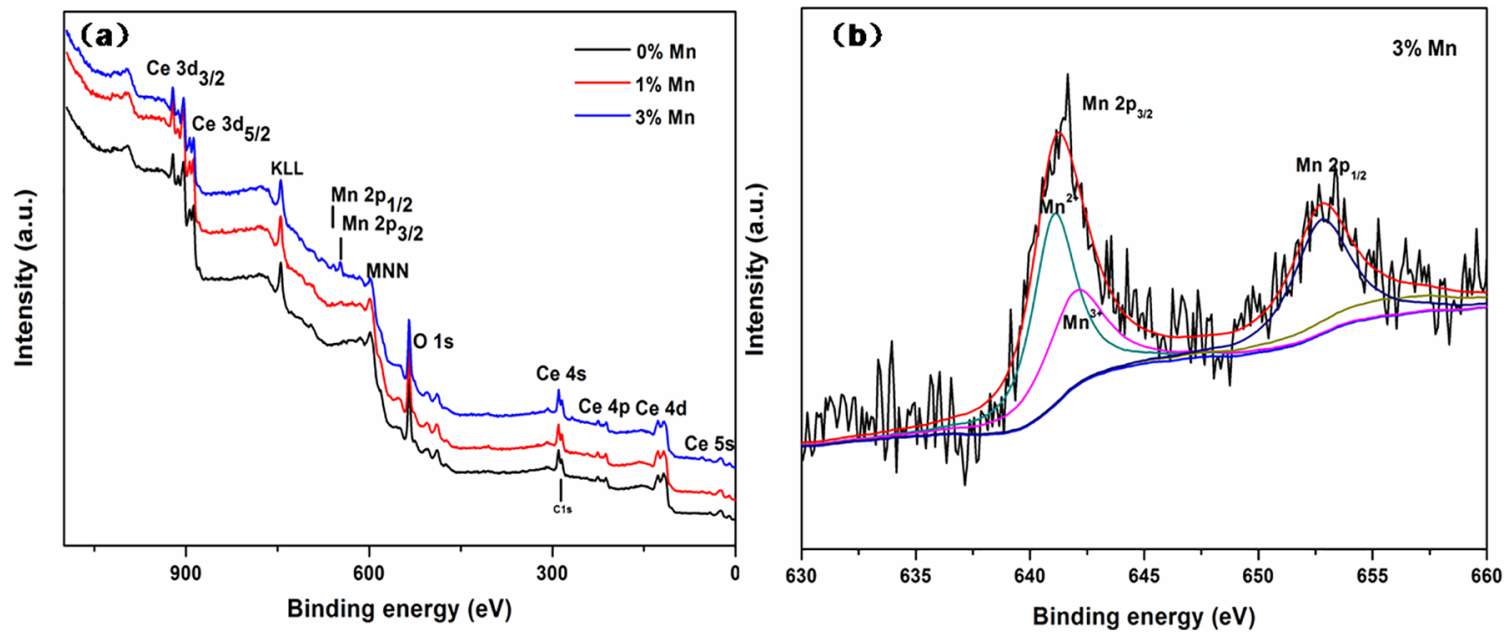

Figure 5. XPS spectra (a) survey spectrum and (b) $\mathrm{Mn} 2 \mathrm{p}$ for $3 \% \mathrm{Mn} / \mathrm{CeO}_{2}$ sample 

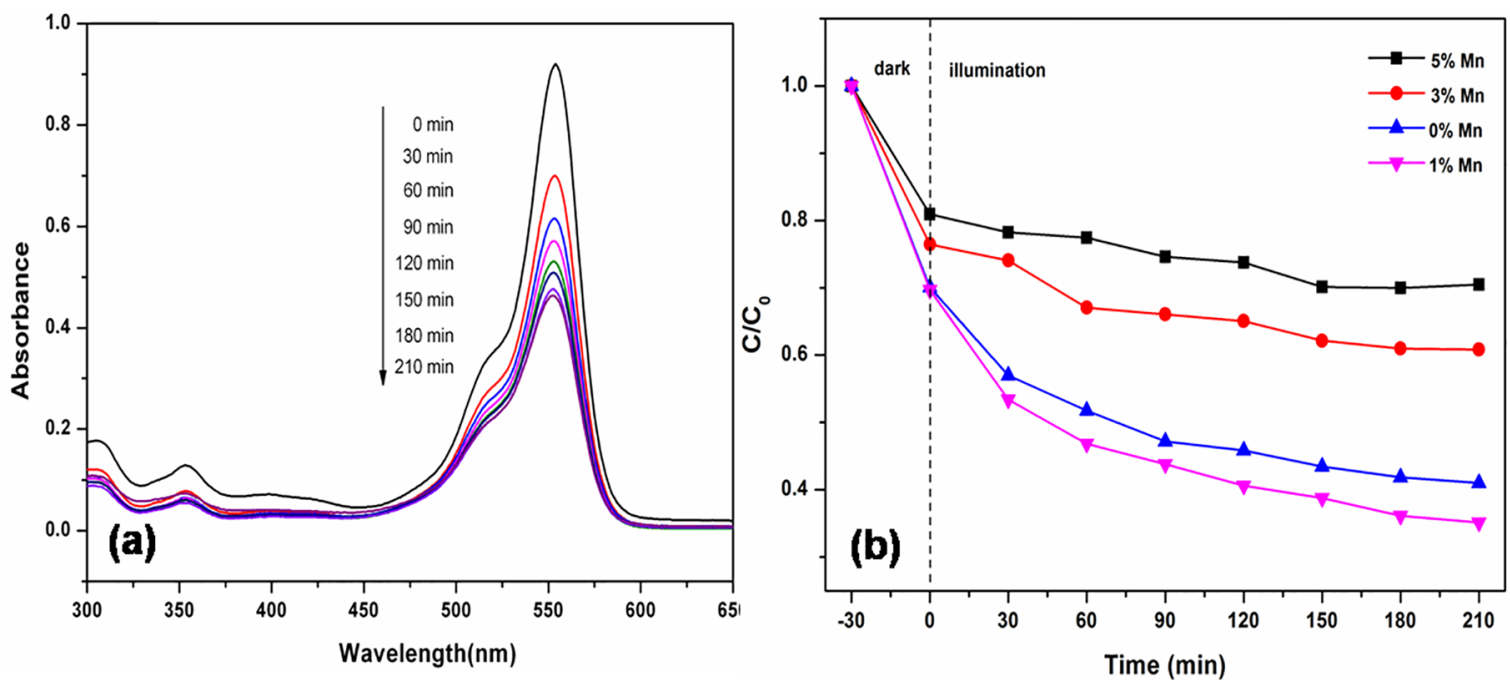

Figure 6. (a) UV-vis spectral variations of $\mathrm{RhB}$ solution over $1 \% \mathrm{Mn}$ doped $\mathrm{CeO}_{2}$ under ultraviolet light irradiation; (b) Degradation of $\mathrm{RhB}$ solutions over $\mathrm{CeO}_{2}$ and $\mathrm{Mn}$ doped $\mathrm{CeO}_{2}$ with different $\mathrm{Mn}$ concentrations under ultraviolet light

\section{Conclusions}

In summary, we have synthesized a series of $\mathrm{Mn} / \mathrm{CeO}_{2}$ photocatalysts by a facile one-step composite-hydroxidemediated approach. This work focuses on understanding of the effects of the $\mathrm{Mn}$ addition in $\mathrm{Mn}$-doped $\mathrm{CeO}_{2}$ nanoflowers. Noticeably, there was an optimal Mn doping concentration in $\mathrm{CeO}_{2}$ samples for the ultraviolet light photocatalysis. Experiments showed that $1 \% \mathrm{Mn}$-doped $\mathrm{CeO}_{2}$ had higher photocatalytic capability compared with that of the pure $\mathrm{CeO}_{2}$ or $3 \%$ and $5 \% \mathrm{Mn}$ ion-doping catalyst. The enhancement in redox efficiency of $\mathrm{CeO}_{2}$ samples upon $\mathrm{Mn}$ doping may be due to the increase in charge transport rate.

\section{Acknowledgements}

This research was financially supported by the Natural Science Foundation of AnHui Provincial Education Department (KJ2016A102), Anhui Provincial Natural Science Foundation (1808085ME138), Graduate student Innovation Fund of Anhui University of Technology and National Undergraduate Training Programs for Innovation and Entrepreneurship (201710360024, 201710360026)

\section{References}

1. Li L, Wang HR, Zou L, Wang X. Controllable synthesis, photocatalytic and electrocatalytic properties of $\mathrm{CeO}_{2}$ nanocrystals. RSC Advances. 2015;5(52):41506-41512.

2. Lu X, Zhai T, Cui H, Shi J, Xie S, Huang Y, et al. Redox cycles promoting photocatalytic hydrogen evolution of $\mathrm{CeO}_{2}$ nanorods. Journal of Materials Chemistry. 2011;21(15):5569-5572.

3. Rangaswamy A, Venkataswamy P, Devaiah D, Ramana S, Reddy BM. Structural characteristics and catalytic performance of nanostructured $\mathrm{Mn}$-doped $\mathrm{CeO}_{2}$ solid solutions towards oxidation of benzylamine by molecular $\mathrm{O}_{2}$. Materials Research Bulletin. 2017;88:136-147.

4. Li SX, Cai JB, Wu XQ, Liu BW, Chen QY, Li YH, et al. $\mathrm{TiO}_{2} @ \mathrm{Pt} @ \mathrm{CeO}_{2}$ nanocomposite as a bifunctional catalyst for enhancing photo-reduction of $\mathrm{Cr}(\mathrm{VI})$ and photo-oxidation of benzyl alcohol. Journal of Hazardous Materials. 2018;346:5261.

5. Li BX, Zhang BS, Nie SB, Shao LZ, Hu LY. Optimization of plasmon-induced photocatalysis in electrospun $\mathrm{Au} / \mathrm{CeO}_{2}$ hybrid nanofibers for selective oxidation of benzyl alcohol. Journal of Catalysis. 2017;348:256-264.

6. Tanaka A, Hashimoto K, Kominami H. Selective photocatalytic oxidation of aromatic alcohols to aldehydes in an aqueous suspension of gold nanoparticles supported on cerium(IV) oxide under irradiation of green light. Chemical Communications. 2011;47(37):10446-10448.

7. Zhang P, Liu Y, Tian BZ, Luo YS, Zhang JL. Synthesis of coreshell structured $\mathrm{CdS} @ \mathrm{CeO}_{2}$ and $\mathrm{CdS} @ \mathrm{TiO}_{2}$ composites and comparison of their photocatalytic activities for the selective oxidation of benzyl alcohol to benzaldehyde. Catalysis Today. 2017;281(Pt 1):181-188.

8. Song S, Xu L, He Z, Ying H, Chen J, Xiao X, et al. Photocatalytic degradation of C.I. Direct Red 23 in aqueous solutions under UV irradiation using $\mathrm{SrTiO}_{3} / \mathrm{CeO}_{2}$ composite as the catalyst. Journal of Hazardous Materials. 2008;152(3):1301-1308.

9. Zou ZJ, Xie CS, Zhang SS, Yu XL, Zou T, Li J. Preparation and photocatalytic activity of $\mathrm{TiO}_{2} / \mathrm{CeO}_{2} / \mathrm{Bi}_{2} \mathrm{O}_{3}$ composite for Rhodamine $\mathrm{B}$ degradation under visible light irradiation. Journal of Alloys and Compounds. 2013;581:385-391.

10. Lu XW, Li XZ, Qian JC, Miao NW, Yao C, Chen ZG. Synthesis and characterization of $\mathrm{CeO}_{2} / \mathrm{TiO}_{2}$ nanotube arrays and enhanced photocatalytic oxidative desulfurization performance. Journal of Alloys and Compounds. 2016;661:363-371.

11. Pavasupree S, Suzuki Y, Pivsa-Art S, Yoshikawa S. Preparation and characterization of mesoporous $\mathrm{TiO}_{2}-\mathrm{CeO}_{2}$ nanopowders 
respond to visible wavelength. Journal of Solid State Chemistry. 2005;178(1):128-134.

12. Hu S, Zhou F, Wang L, Zhang J. Preparation of $\mathrm{Cu}_{2} \mathrm{O} / \mathrm{CeO}_{2}$ heterojunction photocatalyst for the degradation of Acid Orange 7 under visible light irradiation. Catalysis Communications. 2011;12(9):794-797.

13. Mao C, Zhao Y, Qiu X, Zhu J, Burda C. Synthesis, characterization and computational study of nitrogen-doped $\mathrm{CeO}_{2}$ nanoparticles with visible-light activity. Physical Chemistry Chemical Physics. 2008;10(36):5633-5638.

14. Belén Jorge A, Fraxedas J, Cantarero A, Williams AJ, Rodgers J, Attfield JP, et al. Nitrogen doping of ceria. Chemistry of Materials. 2008;20(5):1682-1684.

15. Zhou K, Wang X, Sun X, Peng Q, Li Y. Enhanced catalytic activity of ceria nanorods from well-defined reactive crystal planes. Journal of Catalysis. 2005;229(1):206-212.

16. Ren J, Liu X, Gao RH, Dai WL. Morphology and crystal-plane effects of $\mathrm{Zr}$-doped $\mathrm{CeO}_{2}$ nanocrystals on the epoxidation of styrene with tert-butylhydroperoxide as the oxidant. Journal of Energy Chemistry. 2017;26(4):681-687.

17. Corma A, Atienzar P, Garcia H, Chane-Ching JY. Hierarchically mesostructured doped $\mathrm{CeO}_{2}$ with potential for solar-cell use. Nature Materials. 2004;3(6):394-397.

18. Prabaharan DDM, Sadaiyandi K, Mahendran M, Sagadevan S. Investigating the effect of $\mathrm{Mn}$-doped $\mathrm{CeO}_{2}$ nanoparticles by coprecipitation method. Applied Physics A. 2018;124(2):86.

19. Shao $\mathrm{G}$. Electronic structures of manganese-soped rutile $\mathrm{TiO}_{2}$ from first principles. The Journal of Physical Chemistry C. 2008;112(47):1867718685.

20. Shao G. Red shift in manganese- and iron-doped $\mathrm{TiO}_{2}$ : a DFT $+\mathrm{U}$ analysis. The Journal of Physical Chemistry C. 2009;113(16):68006808 .

21. Yang Y, Li Y, Zhu L, He H, Hu L, Huang J, et al. Shape control of colloidal $\mathrm{Mn}$ doped $\mathrm{ZnO}$ nanocrystals and their visible light photocatalytic properties. Nanoscale. 2013;5(21):10461-10471

22. Ullah R, Dutta J. Photocatalytic degradation of organic dyes with manganese-doped $\mathrm{ZnO}$ nanoparticles. Journal of Hazardous Materials. 2008;156(1-3):194-200.

23. Abdollahi Y,AbdullahAH, Gaya UI, Zainal Z, Yusof NA. Enhanced photodegradation of o-cresol in aqueous $\mathrm{Mn}(1 \%$ )-doped $\mathrm{ZnO}$ suspensions. Environmental Technology. 2012;33(10-12):1183-1189.
24. Lu Y, Lin Y, Xie T, Shi S, Fan H, Wang D. Enhancement of visible-light-driven photoresponse of $\mathrm{Mn} / \mathrm{ZnO}$ system: photogenerated charge transfer properties and photocatalytic activity. Nanoscale. 2012;4(20):6393-6400.

25. Chen Z, Li Y, Guo M, Xu F, Wang P, Du Y, et al. One-pot synthesis of $\mathrm{Mn}$-doped $\mathrm{TiO}_{2}$ grown on graphene and the mechanism for removal of $\mathrm{Cr}(\mathrm{VI})$ and $\mathrm{Cr}(\mathrm{III})$. Journal of Hazardous Materials. 2016;310:188-198.

26. Deng QR, Xia XH, Guo ML Gao Y, Shao G. Mn-doped $\mathrm{TiO}_{2}$ nanopowders with remarkable visible light photocatalytic activity. Materials Letters. 2011;65(13):2051-2054.

27. Tan J, Zhang W, Lv YH, Xia AL. Facile preparation of $\mathrm{Mn}$-doped $\mathrm{CeO}_{2}$ submicrorods by composite-hydroxide-saltmediated approach and their magnetic property. Materials Research. 2013;16(4):689-694.

28. Murugan B, Ramaswamy AV, Srinivas D, Gopinath CS, Ramaswamy V. Nature of manganese species in $\mathrm{Ce}_{1-x} \mathrm{MnxO}_{2-\mathrm{d}}$ solid solutions synthesized by the solution combustion route. Chemistry of Materials. 2005;17(15):3983-3993.

29. Van Overstraeten RJ, Mertens RP. Heavy doping effects in silicon. Solid State Electronics. 1987;30(11):1077-1087.

30. Pavan Kumar CHSS, Pandeeswari R, Jeyaprakash BG. Structural, morphological and optical properties of spay deposited $\mathrm{Mn}$-doped $\mathrm{CeO}_{2}$ thin films. Journal of Alloys and Compounds. 2014;602:180-186.

31. Spanier JE, Robinson RD, Zhang F, Chan SW, Herman IP. Size-dependent properties of $\mathrm{CeO}_{2-y}$ nanoparticles as studied by Raman scattering. Physical Review B. 2001;64(24):245407.

32. Fernández-García M, Martínez-Arias A, Hanson JC, Rodriguez JA. Nanostructured oxides in chemistry: characterization and properties. Chemical Reviews. 2004;104(9):4063-4104.

33. Cong CJ, Liao L, Liu QY, Li JC, Zhang KL. Effects of temperature on the ferromagnetism of Mn-doped $\mathrm{ZnO}$ nanoparticles and $\mathrm{Mn}$-related raman vibration. Nanotechnology. 2006;17(5):1520.

34. Choi WY, Termin A, Hoffmann MR. The role of metal ion dopants in quantum-sized $\mathrm{TiO}_{2}$ : correlation between photoreactivity and charge carrier recombination dynamics. The Journal of Physical Chemistry. 1994;98(51):1366913679. 